\title{
Investment in Sustainable Development: A UK Perspective on the Business and Academic Challenges
}

\section{Nigel Garland $^{1, *}$, Mark Hadfield ${ }^{2}$, George Howarth ${ }^{3}$ and David Middleton ${ }^{4}$}

1 Sustainable Design Research Centre, School of Design, Engineering and Computing, Bournemouth University, Bournemouth, BH12 5BB, UK

2 Research and Enterprise, School of Design, Engineering and Computing, Bournemouth University, Bournemouth, BH12 5BB, UK; E-Mail: mhadfield@bournemouth.ac.uk

3 School of Design, Engineering and Computing, Bournemouth University, Bournemouth, BH12 5BB, UK; E-Mail: ghowarth@btconnect.com

4 Business Council for Sustainable Development-UK, Floodgate Street, Birmingham, B5 5SL, UK; E-Mail: DavidM@ebc-info.co.uk

* Author to whom correspondence should be addressed; E-Mail: ngarland@ bournemouth.ac.uk; Tel.: +44-12-0296-1509; Fax: +44-12-0296-5314.

Received: 22 September 2009 / Accepted: 24 November 2009 / Published: 27 November 2009

\begin{abstract}
There are many legislative, stakeholder and supply chain pressures on business to be more 'sustainable'. Universities have recognised the need for graduate knowledge and understanding of sustainable development issues. Many businesses and universities have responded and introduced Sustainable Development models into their operations with much of the current effort directed at climate change. However, as the current worldwide financial crisis slowly improves, the expectations upon how businesses operate and behave are changing. It will require improved transparency and relationships with all stakeholders, which is the essence of sustainable development. The challenges and opportunities for both business and universities are to understand the requirements of sustainable development and the transformation that is required. They should ensure that knowledge is embedded within the culture of the organisation and wider society in order to achieve a sustainable future.
\end{abstract}

Keywords: sustainable development; business; design; education 


\section{Introduction}

Sustainable development is a complex and diverse subject covering a wide range of disciplines. The Brundtland report defined it as "development that meets the needs of the present without compromising the ability of future generations to meet their own needs" [1], however the range and scope of interpretation varies between practitioners, dependent upon their perspective, field and their audience. An early report for the World Bank on sustainable development concepts found more than fifty definitions [2], while the range of assessment methodologies has been found to be equally varied with more than forty recently compared [3]. The scope for interpretation can also lead to differences within the same organisation; a recent paper found discourse within the OECD in how sustainable development is assessed through two key measures: economic surveys and environmental performance reviews [4]. Although there are differences between concepts and implementations of models, both within the wider field and the work discussed here, the majority share a common theme laid out in the Brundtland report and engage with the social, environmental and economic domains. It has been argued that defining the basic idea of sustainability is straightforward, the real problem is one of identifying what can be sustained, what should be sustained, and for how long [5].

The very nature of the subject leads those practicing within business and engineering \& design education to over simplify or cherry pick topics of interest. It is very easy to merely focus upon the environmental or, for those within business and commerce, to ignore all but the economic factors. However, for businesses to be successful in the future, all members of the organisation should be engaged with and understand the concepts of sustainable development. Those involved in engineering and design accredited to a professional institution are required to understand and implement the concepts of sustainable development [6]; therefore it is essential that the concepts of sustainable development are in place at an academic level. The knowledge and understanding provided by academia should, as a minimum, meet with the needs of the business community and guidance provided by the relevant professional institutions. However, business needs should not be seen as a limiting factor, nor should perceived needs be allowed to cloud judgement [7].

The recent "credit crunch" brought home the realities of unsustainable business models, products and services; especially within the financial sector. The chairman of the Financial Services Authority (the FSA regulate most of the financial services markets, exchanges and firms operating within the UK), Lord Turner, recently asked "..consider what percentage of highly intelligent people from our best universities went into financial services?" and commented "...some of it is socially useless activity" [8]. Within the financial sector and the wider business community, the failure of non-resilient or unsustainable business models has been stark. However, some businesses are adopting the principles and concepts of sustainable development within their models and decision making processes, often through membership of sustainable business networks [9]. The range and scope has been wide with best practice models encompassing social, environmental and economic attributes. Businesses essentially deal with three key elements - people, processes and products. Each must adopt sustainable development principles but the key for businesses are the products and the services they provide.

The formal origins of education for sustainable development (ESD) can be traced back to 1992 and the United Nations Agenda 21 programme of action from the Earth Summit at Rio [10]. For higher education the drive for sustainable development education within the design and engineering 
curriculum has been widespread for at least a decade. However, much of the focus has been towards the aspects of environmental impact, recycling and materials; essentially eco-design [11,12]. There have been misinterpretations in the very meaning of sustainable development [13], both from academics and students alike as well as resistance to embedding within the curriculum [7]. This paper examines the sustainability challenges faced within higher education and business, the different approaches to sustainability and asks how they can be reconciled. The business challenge is examined from the perspective of the Business Council for Sustainable Development: UK (BCSD:UK) focusing on three key areas of future risk, resource exposure and energy security. The Educational challenge is examined from engineering design education and the problems associated with embedding sustainable development into the curriculum.

\section{The Business Challenge}

In 2006 the Stern Review declared that society had to transform to meet the challenges of climate change [14]. The cost of transformation to society would be $1 \%$ of GDP, a figure they would later more than double [15]. Society (and business) has to transform and although the cost of transformation is significant, it should be viewed as an investment. This would be an investment in the development of new technologies, products and services that will make the transformation possible. Since investment and development will largely come from the business community, the transformation process should be seen as the most significant opportunity for businesses since the industrial revolution. The challenge faced by business is one of identifying the pathways and associated risks to achieving this transformation.

\section{Future Risks to Business Sustainability}

For a business to be sustainable it must consider every element of its structure and activities and ask itself — can this be maintained at length without interruption or weakening and at what cost to society? In other words, is it sustainable? It does not refer to, as some have conveniently translated, sustainable economic growth [16].

The lessons learned from the crisis can help business to examine their current models for resilience to future challenges. The Business Council for Sustainable Development: UK (BCSD:UK) recently convened a series of workshops aimed at addressing future risks to business sustainability by examining (amongst others) the lessons from the "credit-crunch", the risks from resource exposure and best practice in energy security.

In February 2009, sponsored by the UK Government, the BCSD-UK staged a workshop at the Department for Business, Enterprise and Regulatory Reform (BERR, replaced by the Department of Business, Innovation and Skills) Future Focus facility [17]. Participants from leading international businesses (BERR, Sustainable Development Commission, Amey, Rolls-Royce, Sun Microsystems, Lloyds Banking Group, Gucci and Faber Maunsell amongst others) asked:

"If we manifestly were ill prepared for a credit crunch, then how ill prepared are we for other potential 'crunches'?" 
During the workshop, a simple five step template for business (Table 1) was tested with participants generating a table of behaviours that contributed to resilience or vulnerability to the credit crunch.

Table 1. Managing risk — anticipating change: a five step model; adapted from [9].

\begin{tabular}{|c|c|}
\hline Analysis & $\begin{array}{l}\text { Analyse the lessons for your business from the credit crunch. } \\
\text { Identify sustainable and unsustainable behaviours. }\end{array}$ \\
\hline 2020 Risks & $\begin{array}{l}\text { Backcast from } 2020 \text { to map the challenges ahead. } \\
\text { Develop capacity, prioritise and manage for disruptive risks. }\end{array}$ \\
\hline Resilience & $\begin{array}{l}\text { Is your company fit for purpose? } \\
\text { Build a sustainable business model. } \\
\text { Understand the businesses fundamental proposition and design } \\
\text { products, services and processes for resilience. }\end{array}$ \\
\hline Stakeholders & $\begin{array}{l}\text { Reframe dialogue with stakeholders. } \\
\text { Help change the context in which business operates. } \\
\text { Engage stakeholders in the process of change. }\end{array}$ \\
\hline Synchronise & $\begin{array}{l}\text { Synchronise actions in-house and across business. } \\
\text { Commit to leadership and help drive business transformation. }\end{array}$ \\
\hline
\end{tabular}

These behaviours were then used as terms of reference for developing nine future risk categories (Figure 1). The nine risk categories were assessed for risks and opportunities that may be encountered when looking back from 2020. The model used was a common vision of a low carbon future based upon the UK's transition plan [18] but viewed from the participants own perspective. Although the perspectives and sustainable business models differed between organisations and their operating environments, a common set of key factors was found, against which resilience could be measured.

Figure 1. Backcasting to indentify key factors and measures of resilience.

\begin{tabular}{|c|c|c|c|c|}
\hline 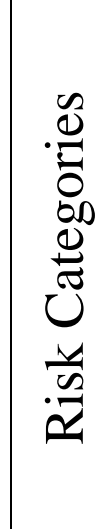 & $\begin{array}{l}\text { Resources } \\
\text { Society } \\
\text { Demographics } \\
\text { Environment } \\
\text { Regulation } \\
\text { Technology } \\
\text { Political } \\
\text { Markets } \\
\text { Process }\end{array}$ & $\begin{array}{l}\text { Backcast } \\
\text { from 2020: } \\
\text { Identify } \\
\text { key factors }\end{array}$ & 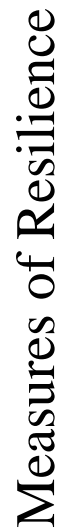 & $\begin{array}{l}\text { Resource efficiency } \\
\text { Effective risk management } \\
\text { Product service mix } \\
\text { Triple bottom line performance } \\
\text { Long-term shareholder interests } \\
\text { Roots in the community } \\
\text { Continuity of operation }\end{array}$ \\
\hline
\end{tabular}

Any sustainable business model should consider three core systems: The fundamental proposition, Product/service solution and the process/supply chain. The participants concluded that they were not well prepared, that current business models "need a major make over" and "business as usual from 'pre-the credit crunch' is a redundant concept". 


\section{Resource Exposure}

BCSD-UK's Resource Respect programme asks: what businesses are critical to the sustainability of an area-a city, a region, a local community; what resources are critical to those critically important businesses? If those resources are under pressure from changing global buying habits, increased population levels, increased industrialisation or climate change, those essential businesses may be under threat. If they fail, the social consequences to the local community could be dire.

The BCSD-UK, in conjunction with the Carbon Action Yorkshire initiative, staged a workshop hosted by WSP Environmental in Leeds. Some of the key issues they identified were that there is more vulnerability to water shortage in the UK than is generally understood and that there is no National Water Strategy. Businesses in some parts of the UK (particularly the South East) could suffer because of water shortages.

Delegates from both British Waterways and Scottish and Newcastle (one of the world's largest producers of alcoholic beverages, acquired by Heineken and Carlsberg for £7.8bn in May 2008) highlighted the risks posed to existing business models by the Environment Agency's Catchment Abstraction Management Strategies (CAMS) [19]. Essentially, the CAMS manage water extraction within each catchment area. They also replace licences of right, instead issuing time limited licences. The expiry dates for the licences range from 2015 in stressed areas through to 2026 in less stressed areas. The Environment Agency also proposes to allow trading of abstraction licences, freeing up resources where supply is abundant [20]. Therefore, business should have water management on their risk register, not just because of loss of abstraction rights and the likely increases in cost as supply is reduced, but the potential rewards from trading when efficiencies are exceeded.

With regard to assessing the water resource exposure to business, water foot-printing can be used to ascertain not just the direct the indirect risks, throughout the supply chain [21]. For example: Scottish and Newcastle use a lot of aluminium cans, aluminium which requires huge amounts of energy which is typically from hydroelectric schemes, will there be enough water for these? Clearly, for a major brewer, water security is one of the most significant risks to their business, not just directly in the brewing process, but indirectly through their suppliers of grain (farm production) and aluminium packaging.

\section{Energy Security}

BCSD-UK became involved in exploring the subject of decentralised energy after participating in the UK Government's Business Taskforce on Sustainable Consumption and Production. A number of exploratory workshops were staged around the UK and it became clear that one of the inhibitors to progress is lack of understanding of what decentralised energy means. As a result BCSD-UK's Energy Group, led by E.ON, developed a guide to decentralised energy [22].

A number of BCSD-UK members have examined the issue of security of energy supply and have seen that renewable energy, produced local to their needs and off-grid, enhances their control over such a critical resource. This can be very attractive so far as environmental and carbon footprint issues are concerned, especially if the energy is produced from their own waste stream. Two examples of biomass generation have been highlighted in a recent case study report on best practice [23]. 
The first case is that of Ecclesham Biomass where a 2.6MW generator is primarily fuelled by the energy crop Miscanthus and wood chips. All of the fuel is sourced within 20 miles of the plant, therefore supporting the local economy, providing local employment as well as bio-diversification within the local environment.

The second case is that of Scottish and Newcastle's progress with one of the largest industrial renewable/waste to energy projects of its kind in the UK. Their breweries produce thousands of tonnes of spent grain as a by-product of the brewing process. This by-product has significant potential as a renewable biomass fuel, with energy content comparable to wood chip. By installing Combined Heat and Power (CHP) biomass fuelled boilers at two of its breweries they are able to reduce their UK manufacturing $\mathrm{CO}_{2}$ emissions by some $40 \%$. This can provide the two breweries with $70 \%$ renewable energy, generated and used on site. Royal Brewery (Manchester) began commissioning in spring 2009 and John Smiths Brewery (Tadcaster) in summer 2009.

Both case studies provide alternative routes to sustainable decentralised energy production. The first case provides social, economic and environmental benefits to the local communities. The second provides energy security to a major business enterprise and reduces their environmental impact. Both schemes have, however, encountered problems with the Environment Agency when classifying by-products as bio-mass rather than waste, problems that have had a significant impact upon the viability of these projects. In fact, in the case of the Scottish and Newcastle project, it would not have been viable on a purely economic basis.

\section{The Educational Challenge}

The transformation that is faced by society will require investment in new technologies and innovation in product and service provision. For business, this will mean designers and engineers must be not only conversant with the principles of sustainable development but fully engaged. This represents a significant challenge for design and engineering within higher education. The challenge faced by universities is reflected in international efforts such as the United Nations Decade of Education for Sustainable Development (DESD). The international implementation scheme's overall goal for DESD is [10]:

“...to integrate the principles, values, and practices of sustainable development into all aspects of education and learning. This educational effort will encourage changes in behaviour that will create a more sustainable future in terms of environmental integrity, economic viability, and a just society for present and future generations."

\section{Misconceptions of Sustainable Development within the Design Curriculum}

There has, in recent years, been a drive to embed sustainable development into the design curriculum within international university programmes. Despite this, and the clear reference to the social sphere of sustainability within the wider literature, this aspect does not appear to have embedded into the design curriculum of Higher Education (HE) within the UK. As is common across the HE sector, there are misinterpretations over the very concept of sustainable development within design education. A study by Ramirez ([24], cited [13]) showed that (in the opinion of the lecturers 
questioned) $72 \%$ of Industrial Design students understood "sustainable design issues and strategies". Ramirez, however, identifies that the lack of distinction by those academics between ecological design or green design and sustainable design. This aspect of misconception extends into the business environment and was explored by surveying academics (Institution of Engineering Designers accredited courses), students (Product Design; Bournemouth University) and employers (placement and graduate) within the UK [13]. Respondents believed they had a working knowledge or high understanding of sustainable design issues and strategies. However, academics, students and employers alike generally had a poor understanding of sustainability. Definitions were at best about minimising environmental impact, recycling and reducing the carbon footprint; essentially eco-design.

The misconceptions over sustainability may be understandable given the limited scope within undergraduate design courses for adding additional units to explore the topic in depth and the fear of dilution [7]. However, it can be argued that it is not a matter of providing additional units or diluting the existing content, rather a change in culture, with emphasis upon the reflected values and goals of the students design process and output. The engineering department at Cambridge University found a familiar set of barriers to change: "...perceived threats to the integrity of subject material, ...low intra-departmental interaction, ... successful tradition ... and a sceptical attitude to change.” [25]. They also found a tension caused by the introduction of "subjectivity and judgement" while traditional engineering methodologies were challenged by the broader scope or open ended nature of sustainable development.

\section{Approaches to Embedding Sustainable Development}

Approaches to integration of sustainable development have varied across and within universities. Delft University of Technology in the Netherlands has adopted a three stage strategy [26]:

1. All students take an introductory course "Technology in sustainable development".

2. The concepts of sustainable development are embedded into all regular courses.

3. Provide a "sustainable development specialisation" within each faculty.

Provided within the specialisation programme, is a compulsory course that Delft term "boat week". Here final year students of various technical background and discipline take part in lectures, seminars and various group activities. Since it is on a boat, no one can leave and full participation is assured. After the boat week the students are taught basic participatory backcasting techniques as part of a follow up course [27]. Boat week itself frames the context for the follow up as it is during this exercise that students appreciate the complexity and depth of sustainability problems. Although the course does not purport to create experts, it does offer a flavour or light version of backcasting. Although the scheme appears to work well, a study of Industrial Design Engineering students at Delft examined the integration and uptake of sustainable development methodologies into regular design courses and found that "unless specifically asked to integrate sustainability issues, students have no incentive to proceed with them..." [28]. During the course students had to be reminded that sustainable development was more than the environment, defining it as "beneficial to society". Engaging students was particularly difficult when related to social issues; only through emphasising the social nature of "safety issues" could some students contribute to this aspect. The problem with engaging the students 
at Delft with the concept of sustainability is not uncommon. Indeed, a recent study of 200 undergraduate design students found the design priorities of students to be a direct reflection of their purchasing aspirations with quality, aesthetics and cost factors outweighing sustainability issues [29].

At Cambridge University (UK) the process of embedding sustainable development within the engineering department has evolved "opportunistically" over time [25]. Key to their implementation was the establishment of a core of expertise in sustainable development teaching. Although early focus was placed upon postgraduate this was expanded to include undergraduate courses. Within this context sustainable development lecturers are given to first year undergraduate students as well as integration with a compulsory project unit. In formalising the process they believed that embedding required "...a cultural shift, not just the provision of an extra optional course or two." Essentially, the approach has been to encourage students to question their own assumptions and reflect upon a wider range of perspectives.

At the University of Manchester (UK) an interdisciplinary course on sustainable development has been introduced to engineering and physical sciences programmes [30]. Cross disciplined groups of third year undergraduate students work on a range of sustainability problems. Problem based learning (PBL) rather than formal teaching is used, with the responsibility for learning resting with the student. Each problem set is a "wicked problem" in that there is no definitive answer [31] and while the groups are assisted by facilitators, students learn through investigation, collaboration and reflection. A number of issues arose from the pilot study, significantly: The course was not formally assessed while many wished it had been, all students were drawn from the third year yet drew comments such as "why couldn't we learn this way before?" The Authors suggest that students should be engaged with sustainable development through PBL from an earlier stage.

At Bournemouth University (UK) sustainable development has been integrated within the design curriculum through two distinct paths: embedding within the existing framework and developing discrete Sustainable Design courses. This approach has been adopted for both undergraduate and postgraduate programmes within the Design Group as well as at doctoral and post-doc through the Sustainable Design Research Centre (SDRC). At undergraduate level, sustainability has been introduced through specific units such as "sustainability in the built environment", project units and a specific course "BSc Sustainable Design" although this has subsequently been withdrawn. Within the postgraduate framework specific units and courses have been offered for several years, "MSc Sustainable Product Design" includes three sustainability orientated units and requires the final dissertation to reflect a relevant issue. Both the undergraduate and postgraduate programmes have benefitted from the interactive online learning and assessment environment detailed below. There has also been a move to provide a framework for teaching staff involving an internal network interfacing with external stakeholders [32].

\section{Institutional Guidance}

The drive for sustainable development within the curriculum is reflected in guidance provided by the Engineering Council UK (ECUK) and initiatives from the Royal Academy of Engineering (RAEng). The engineering competencies published by The ECUK [6] for Engineering Technician, Incorporated and Chartered Engineer requires competencies in Sustainable Design "E3-Undertake 
engineering Activities in a way that contributes to sustainable development". In the case of Chartered Engineers they are required to consider "...environmental, social and economic outcomes simultaneously", “...enhance the quality of the environment and community..." and "Understand and secure stakeholder involvement in sustainable development". The ECUK provides additional guidance for the engineer and lists six principles to "guide and motivate engineers when making decisions for clients, employers and society which affect sustainability” [33]:

1. Contribute to building a sustainable society, present and future

2. Apply professional and responsible judgement and take a leadership role

3. Do more than just comply with legislation and codes

4. Use resources efficiently and effectively

5. Seek multiple views to solve sustainability challenges

6. Manage risk to minimise adverse impact to people or the environment

What is most interesting about these principles is the recognition of broader concepts beyond ecodesign and outside of the engineer's (or designer's) traditional role and circle of influence. Specifically they should understand "relevant social and cultural structures outside of their normal community of practice", the impacts of their decisions may be "global and long-lasting" and they should "consider the views of the community". They should also "be aware that there are inherently conflicting and un-measurable aspects of sustainability".

The RAEng provides higher education with guidance on embedding sustainable development within engineering and design courses through its visiting professors' scheme. The Manchester and Cambridge models (above) and that of Bournemouth (below) have been developed through the RAEng scheme. The scheme was originally launched in 1989 to provide design skills to engineering students. This enabled distinguished senior engineers from the business community to work with academics and enhance links between industry and education. The RAEng recognised that the design function was the key to sustainable products and expanded the scheme to "Engineering Design in Sustainable Development". The scheme successfully supported 26 visiting professors in 28 universities in the first 5 years. The Aim of the scheme was to develop new materials and case studies to embed within the engineering and design curriculum. The scheme led to the development of the RAEng's twelve guiding principles on sustainable development derived from seven case studies [34]. Interestingly, the RAEng principles describe sustainable development (within the context of engineering) as " $a$ new integrative principle, not a new set of tools, so that the concept cannot simply be regarded as an 'addon' to existing engineering skills and educational programmes. "

RAEng and Sustainable Development in Design at Bournemouth University

The RAEng visiting professors' scheme has operated at Bournemouth University since 2000. This has helped to promote sustainability within the design curriculum through the development of an online learning and assessment environment [12,35] and through the Smith and Nephew Sustainable Development Award.

The learning environment has been developed over the past eight years and in addition to an introduction and course materials consists of case studies on Life Cycle Analysis (LCA), Design for Waste (DfW) and Sustainable Product Development (SPD). The LCA and DfW modules include 
online tests to track progress and a bespoke LCA tool "Eco Packager" (Figure 2). DfW also includes product disassembly exercises and both are used at undergraduate and post-graduate level.

Figure 2. SPD Eco Packager Tool [35].

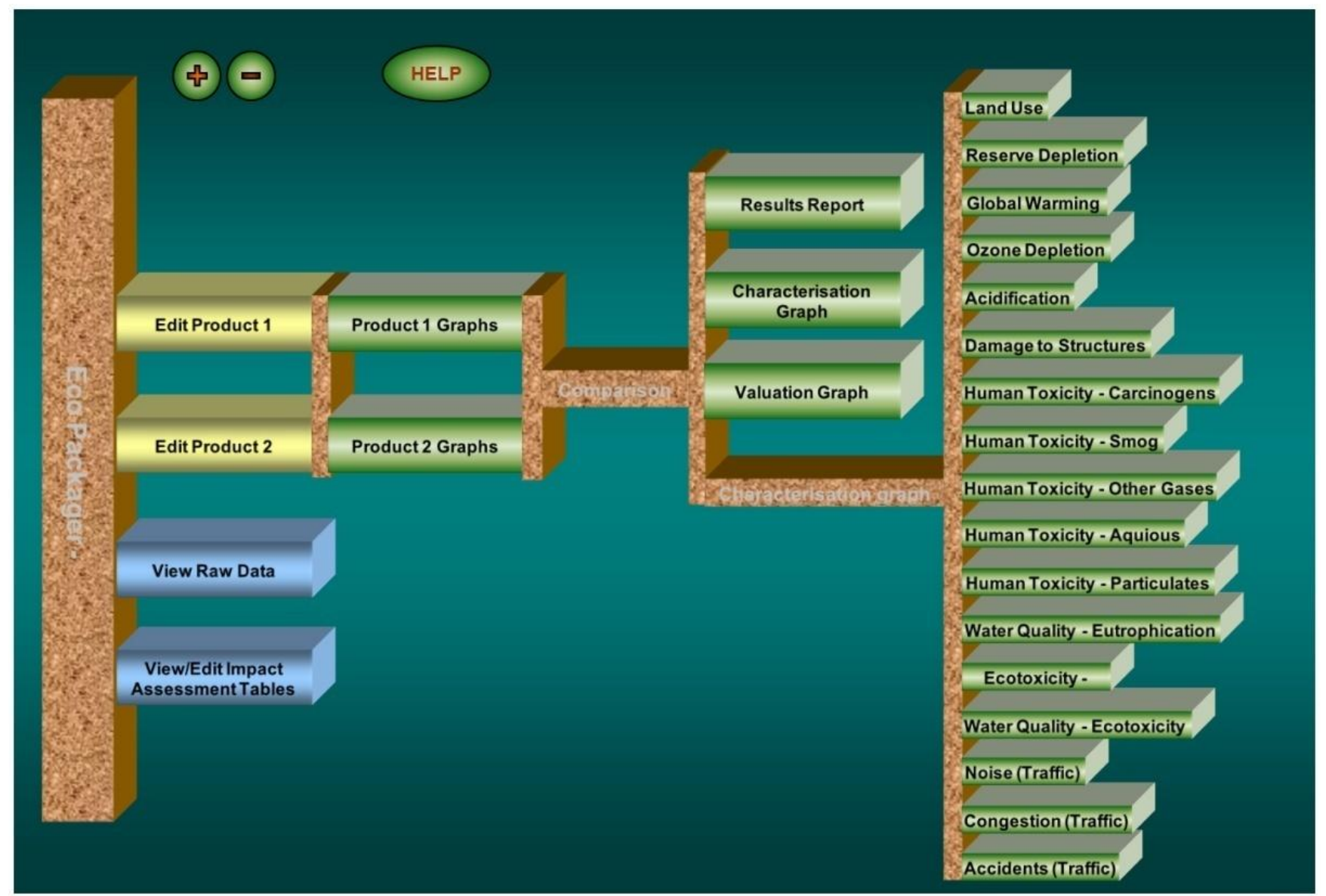

The SPD unit is more complex and covers Economic, Environmental and Social risks and benefits from a number of stakeholder perspectives [36]. The module includes course materials, a risks and benefits mapping tool (Figure 3) and relies upon student's role playing as various stakeholders: CEO, Union official, Local Councillor, Resident and Environmental Activist. Background information is supplied for each of the stakeholders for the role playing exercise. The role playing exercise is critical in getting the students to think beyond the role designer and relate to the wider aspects of sustainability. The values and opinions they express as stakeholders are collated and used to drive the mapping tool. The tool considers not just the product but also the manufacturing site and business operation. However, the complexity of the model leads the module to primarily postgraduate study.

Sustainable development is also incentivised within the university through the Smith and Nephew Award which has been used to promote sustainability within the undergraduate design framework for some nine years. Final year undergraduate design projects are assessed against a range of criteria: environmental, social, economic and design. The award is presented annually and is judged at Bournemouth University's Festival of Design and Innovation. 
Figure 3. SPD Summary Risk and Benefit Assessment [35,36].

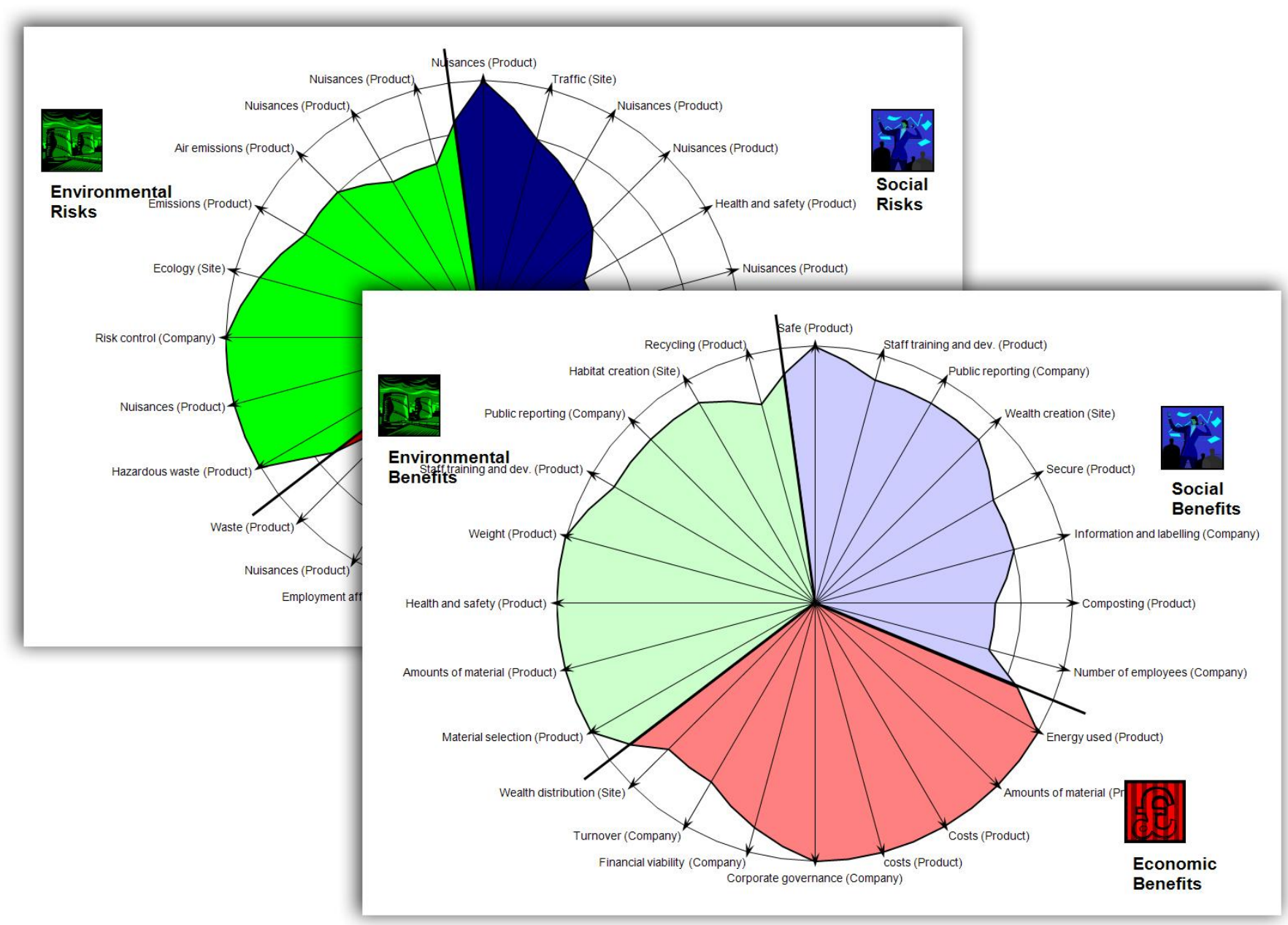

\section{Discussion}

There has been progress in integrating sustainable development into business and education but this has taken nearly two decades. The business examples recognise that social aspects are key to successful future business models yet within design education there has been much less emphasis.

Business appears to be learning from the recent economic crisis and looking at how it can build resilience into its models. In doing so they are looking to the future and trying to understand sustainable development. They also recognise that it can only be delivered if it engages with every aspect of their operation. The five step model demonstrates the need to engage not just internal stakeholders, but those outside the organisation. However, what appears to be an implementation of sustainable development practices could also be regarded as just good management. A study of corporate sustainability by the Institute of Management Development found that most were "...limited to the reduction of downside operational risk and to measures to increase eco-efficiency, the no-brainers of good (rather than corporate sustainability) management" [37]. What is missing from the examples provided is the change in culture, away from consumerism, that will be required for sustainable development [38]. Although there is scope to imply a change through re-evaluating the product/service mix, a recent study of Corporate Social Responsibility also found businesses were 
almost universally failing to address the problem of transforming consumption in a sustainable direction [39]. However, the challenge faced by consumerism is not to be under-estimated. Even when consumers are confronted with the real impact of their lifestyle choices, they will reinforce their existing position and distort their perception of environmental problems [40]. A further problem identified within the studies is the difficulty in managing change when regulatory bodies have established agendas and their own strategic vision. This was the case when re-classifying bio-mass co-product as a fuel source rather than a waste stream. This problem is also found outside of the UK where established forest management strategies have hindered bio-fuelled generating capacity and placed communities at risk from wildfires [41].

Business recognises the need to for sustainable development, even if it has, in the examples provided, been rephrased as resilience. It is also clear that the product, and how it delivers its service, is of paramount importance. The product delivers the public face of the business and provides its interaction with society (as well as its revenue stream) and can dictate the potential impact of sustainable development upon their operations. This is recognised by both the Engineering Council and the RAEng. Therefore, it is essential that design education reflects this is the way it delivers sustainable development to engineering and design students.

Within education there has been difficulty in engaging students with sustainability unless specifically asked to. This may be a case of students looking to contemporary design solutions for inspiration (and aspiration) rather than looking to future design needs. When they are engaged the emphasis is generally toward the environmental aspects with little consideration of the social. Essentially, the wider impact of design decisions appear to be of secondary importance or irrelevant. This also appears to be the case in how sustainable development is viewed by academics, not just within design and engineering, but other disciplines as well. Academia often appears to view sustainable development as another unit to teach rather than an overriding methodology.

Although misinterpretation and misunderstanding of sustainable development has hindered adoption within design engineering education, there has also been some progress. The successful examples described each have PBL at their core, but each is also very different. Each of the examples faced obstacles to implementation, the very nature and complexity of sustainable development made it difficult to teach in a conventional way and presented risks with dilution of existing content or resistance from academic staff. The Delft "boat-week" uses a range of techniques, including group and PBL over a one week period and is offered to final year undergraduate students. The Cambridge approach has been to provide lectures and project work to students from their first year. At Manchester, the approach has been to provide a specific PBL course to cross disciplinary groups of final year students. At Bournemouth the approach has been to deploy an interactive learning environment containing lecture support, PBL, specific tools and Role play. Each of these cases has employed the benefits of using PBL to understand the complexity of sustainable development within a design context. They have also emphasised that embedding sustainable development is about changing the culture, or values, of the students, academics and universities. This is also reflected in the guidance provided by the RAE and by the requirements of ECUK. 
In order to successfully embed sustainable development within the curriculum it must be embedded into the students, staff, university and society as a whole. In essence, it must be a "cultural shift". To encourage this, students need to understand the wider impacts of their decisions, both as designers and in the wider community, as consumers. There needs to be an intrinsic interest in the subject and the ability to apply engineering and design skills to problems outside of their normal sphere. They also need to develop their life-long learning skills. These are key benefits of the examples provided and of PBL as a whole [42]. The resistance faced from academia, even within the successful schemes, reflects the qualitative nature of the social sphere and in many cases results in a limited definition such as ecodesign. Students (and academics) have found the economic and environmental aspects more relevant because they are numerically quantifiable and within the realm of material and technology selection. The shift required within academia needs to encompass the social aspects of sustainable development and the challenge of transforming consumerism.

When considering a simple definition for sustainable development within design education it may be prudent to return to Lord Turners comments on the financial sector (above). Essentially, when considering design it doesn't matter if it's a physical product, financial product or service offering; it can be condensed to two simple questions:

1. Is it socially useful?

2. Is it a waste of the Earth's natural resources?

In other words, does it make a positive contribution to society and does the contribution outweigh the economic, environmental and human costs?

\section{Next Steps}

To provide a primer for first year Design Engineering students a live project incorporating peer assisted learning and PBL methodologies will be used. Students will be asked to solve a design problem within the context of sustainable development linked to a live research problem. The exercise is cross disciplinary as it is directly linked to a Development Partnerships in Higher Education: Department for International Development (DelPHE) funded programme through the School of Health and Social Care as well as the Lagos State University Teaching Hospital, Niger Delta Development Initiative (NDDI) and the Youth Development Initiative (YDI). The project will run continuously during the students' first week of study, during which no other units are taught. Students will be formed into teams of four consisting of first and second year students. They will be issued a brief to design a child's mosquito tent for use (and manufacture) in the Niger Delta region of Nigeria. There will be no didactic element; instead students will present their findings at daily briefings, the first after two hours. After each presentation, students will be asked to reflect upon their findings and those of their peers through open discussions. Students will then consider a number of sustainability problems, each derived from discussions after the presentations. Role-play activity will be used to convey the complexity and diversity of sustainable development, each team representing a different stakeholder. During the final two days the teams will each construct a prototype, justify their design decisions and deliver their final presentation for assessment. The exercise will provide students with an introduction 
to sustainability and a broader appreciation of the breadth and complexity of the subject. It should provide for an understanding of its role within design as well as the opportunity to acquire the self-directed learning skills they will need during their study and professional life.

\section{Conclusions}

In asking the question "is this business sustainable?" it is asking if the business has in built resilience to future shocks and challenges and investing for those opportunities that change brings. The business approach appears more strategic and broad ranging than in design education where, in many cases, only the products direct impacts are considered. Universities and business need to work together to close the gap between their approaches to the delivery of sustainable development.

Sustainable development in design and engineering is about designing products and services for an uncertain future. Merely teaching aspects of sustainability can only focus upon the past, education must enable students to explore the future and question their impact on the wider community. Design students must evaluate the social contribution against the economic, environmental and human cost: Is it socially useful? Or is it a waste of the Earth's natural resources? This approach can be adapted to all aspects of the engineering design curriculum; all that is required are the two simple questions.

The specific case studies have shown how student understanding of sustainable development can be achieved through a problem based learning approach. An intensive problem based course is proposed which encompasses the best aspects of these while engaging a peer assisted learning approach. By engaging both first and second year students within the same groups all students will gain an understanding of the broader concepts of sustainable development. The first year students will also learn the basic design skills directly from their peers while second years will gain experience of managing the design process. The key skill developed from the PBL approach is self-directed learning, something that is essential if students are to develop beyond university through life-long learning.

There are common factors in both the business and educational approaches to sustainable development. Both require participants to examine their proposal from alternative perspectives. Both require a broader understanding of the impacts decision making has, often outside of their traditional sphere of influence. Both require a change in culture: internally, in the way they deliver their service; and externally, within society.

\section{References}

1. World Commission on Environment and Development. Our Common Future; Oxford University: Oxford, UK, 1987.

2. Pezzy, J. Sustainable Development Concepts, An Economic Analysis; World Bank: Washington, DC, USA, 1992.

3. Singh, R.K.; Murty, H.R.; Gupta, S.K.; Dikshit, A.K. An overview of sustainability assessment methodologies. Ecol. Indic. 2009, 9, 189-212. 
4. Lehtonen, M. OECD organisational discourse, peer reviews and sustainable development: an ecological-institutionalist perspective. Ecol. Econ. 2009, (in Press).

5. Costanza, R.; Patten, B.C. Defining and predicting sustainability. Ecol. Econ. 1995, 15, 193-196.

6. UK Standard for Professional Engineering Competence; Engineering Council UK: London, UK, 2008.

7. Jones, P.; Trier, C.J.; Richards, J.P. Embedding Education for Sustainable Development in higher education: a case study examining common challenges and opportunities for undergraduate programmes. Int. J. Educ. Res. 2008, 47, 341-350.

8. Turner, A. How to tame global finance. Prospect Magazine 27 August 2009.

9. Collins, E.; Lawrence, S.; Pavlovich, K.; Ryan, C. Business networks and the uptake of sustainability practices: the case of New Zealand. J. Clean. Prod. 2007, 15, 729-740.

10. United Nations Decade of Education for Sustainable Development (2005-2014): International Implementation Scheme; UNESCO: Paris, France, 2005.

11. Vezzoli, C. A new generation of designers: perspectives for education and training in the field of sustainable design. Experiences and projects at the Politecnico di Milano University. J. Clean. Prod. 2003, 11, 1-9.

12. Hutchings, M.; Garland, N.P.; Hadfield, M.; Howarth, G.; Lewarne, S.; Norman, K. Educational challenges of web-based case studies in sustainable development. In Design and Manufacture for Sustainable Development; Hon, B., Ed.; Professional Engineering, University of Liverpool: Liverpool, UK, 2002; pp. 295-304.

13. Humphries-Smith, T. Sustainable design and the design curriculum. J. Des. Res. 2008, 7, 259-274.

14. Stern, N. The Economics of Climate Change: The Stern Review; Cambridge University: Cambridge, UK, 2006; p. 692.

15. Jowit, J.; Wintour, P. Cost of tackling climate change has doubled, warns Stern. The Guardian June 26, 2008.

16. Daly, H.E. Toward some operational principles of sustainable development. Ecol. Econ. 1990, 2, 1-6.

17. Challenging Convention and Exploring New Models: Developing an Agenda for Action; Business Council for Sustainable Development: Birmingham, UK, 2009.

18. The UK Low Carbon Transition Plan; Department of Energy and Climate Change: London, UK, 2009.

19. Managing Water Abstraction: Interim Update; The Environment Agency: Bristol, UK, 2008.

20. Review of Barriers to Water Rights Trading-Final Report; The Environment Agency: Bristol, UK, 2008.

21. Chapagain, A.K.; Hoekstra, A.Y. The global component of freshwater demand and supply: an assessment of virtual water flows between nations as a result of trade in agricultural and industrial products. Water Int. 2008, 33, 19-32.

22. Decentralised Energy Guide; Business Council for Sustainable Development: Birmingham, UK, 2009. 
23. BCSD-UK Case Studies Report; Business Council for Sustainable Development: Birmingham, UK, 2009.

24. Ramirez, M. Sustainability Integration in Industrial Design Education: a Worldwide Survey. In Proceedings of ConnectED 2007 International Conference on Design Education, University of New South Wales, Sydney, Australia, 2007.

25. Fenner, R.A.; Ainger, C.M.; Cruikshank, H.J.; Guthrie, P.M. Embedding sustainable development at Cambridge University Engineering Department. Int. J. Sustain. High. Educ. 2005, 6, 229-241.

26. Kamp, L. Engineering education in sustainable development at Delft University of Technology. $J$. Clean. Prod. 2006, 14, 928-931.

27. Quist, J.; Rammelt, C.; Overschie, M.; de Werk, G. Backcasting for sustainability in engineering education: the case of Delft University of Technology. J. Clean. Prod. 2006, 14, 868-876.

28. Boks, C.; Diehl, J.C. Integration of sustainability in regular courses: experiences in industrial design engineering. J. Clean. Prod. 2006, 14, 932-939.

29. Reynolds, T.; Hunt, C. The Significance of Purchasing Behavioural Characterisation on Sustainable Design Education of Students. In Proceedings of International Conference on Engineering and Product Design Education, University of Brighton, Brighton, UK, 2009.

30. Tomkinson, B.; Dobson, H.; Tomkinson, R.; Engel, C. An Inter-Disciplinary, Problem-Based Approach to Educating Engineers in Sustainable Development. In Proceedings of International Conference on Engineering Education-CEE 2007, International Network on Engineering Education and Research, Coimbra, Portugal, 2007.

31. Rittel, H.W.J.; Webber, M.M. Dilemmas in a general theory of planning. Policy Sci. 1973, 4, 155-169.

32. Hadfield, M.; Howarth, G. Consolidating Sustainable Development in Engineering Design-Educating the Educators. In Proceedings of EESD 2004 Engineering Education in Sustainable Development: International Conference, Barcelona, Spain, 2004.

33. Guidance on Sustainability for the Engineering Profession; Engineering Council UK: London, UK, 2009.

34. Engineering for Sustainable Development: Guiding Principles; The Royal Academy of Engineering: London, UK, 2005.

35. Bournemouth University Sustainable Product Development Learning Environment. http://spd.bournemouth.ac.uk/ (accessed 28 August 2009).

36. Howarth, G.; Hadfield, M. A sustainable product design model. Mat. Des. 2006, 27, 1128-1133.

37. Salzmann, O.; Ionescu-Somers, A.; Steger, U. The business case for corporate sustainability: literature review and research options. Eur. Manag. J. 2005, 23, 27-36.

38. Goodland, R.; Daly, H.; Kellenberg, J. Burden sharing in the transition to environmental sustainability. Futures 1994, 26, 146-155.

39. Málovics, G.; Csigéné, N.N.; Kraus, S. The role of corporate social responsibility in strong sustainability. J. Socioecon. 2008, 37, 907-918.

40. Kilbourne, W.; Pickett, G. How materialism affects environmental beliefs, concern, and environmentally responsible behavior. J. Bus. Res. 2008, 61, 885-893. 
41. Iversen, K.; van Demark, R. Integrating fuel reduction management with local bioenergy operations and businesses - a community responsibility. Biomass and Bioenergy 2006, 30, 304-307.

42. Norman, G.R.; Schmidt, H.G. The psychological basis of problem-based learning: a review of the evidence. Acad. Med. 1992, 67, 557-565.

(C) 2009 by the authors; licensee Molecular Diversity Preservation International, Basel, Switzerland. This article is an open-access article distributed under the terms and conditions of the Creative Commons Attribution license (http://creativecommons.org/licenses/by/3.0/). 